\title{
Simultaneous effect of surface roughness and passivity on corrosion resistance of metals
}

\author{
A. S. Toloei, V. Stoilov \& D. O. Northwood \\ Department of Mechanical, Automotive and Materials Engineering, \\ University of Windsor, Canada
}

\begin{abstract}
Unidirectional surface roughness of varying magnitudes were created on both nickel and mild steel by grinding on $\mathrm{SiC}$ papers with grit sizes from $\mathrm{G} 60$ (roughest) to G1200 (smoothest) and the corrosion resistance in $0.5 \mathrm{M} \mathrm{H}_{2} \mathrm{SO}_{4}$ solution was determined using a potentiodynamic polarization technique. A different trend of corrosion rate versus roughness was seen for the active-passive metal (nickel) and non-active-passive metal (mild steel). For nickel there was an increase in corrosion rate with increasing roughness, whereas for mild steel the corrosion rate decreased with increasing surface roughness. Furthermore, through a detailed examination of the surface before and after corrosion using techniques including profilometry, scanning electron microscopy (SEM) and energy dispersive spectroscopy (EDS), it was established that different corrosion mechanisms were operative for nickel and mild steel. For both metals, the smaller grit sizes produced a rougher surface with wider and deeper grooves. In the case of nickel, the higher roughness provided a greater contact area between the corrosive medium and metal and there was trapping of the corrosive ions in the deep grooves. Both of these factors would lead to an increase in corrosion rate. Also, for the smoother nickel surfaces, it is easier to form a stable passive film. For mild steel, which does not form a passive film, corrosion rates are generally much higher than for nickel. For the rougher surfaces with the deeper grooves, the corrosion product, $\mathrm{FeSO}_{4}$, can fill the grooves thereby acting as a barrier to further ingress of the corrosive ions to the un-corroded metal.
\end{abstract}




\section{Introduction}

For metallic materials the literature in general, shows that the higher the surface roughness, the higher the corrosion rate. Such a trend was observed for copper, nickel, aluminium, stainless steel, magnesium and titanium alloys [1-6]. In all cases the effect of creating different roughnesses were investigated on both localized and general corrosion performance of the alloys. In contrast, in the case of an AE44 magnesium alloy [7] and mild steel [8] a reverse trend was observed. Alvarez et al. [7] showed that the corrosion rate from polished coupons (with lower roughness value) was notably greater than the corrosion rate from the semi-polished coupons (with higher roughness value) for general corrosion indicating that when the surface roughness was greater, less general corrosion occurred. They claimed that a passivated surface, whether it is aluminum, copper, nickel, titanium alloy or stainless steel, has a higher corrosion potential in comparison with an unpassivated, or active surface such as AE44 magnesium alloy or mild steel. The first category passivates quickly or develops stable oxide films in contact with the atmosphere or water. However, unlike the first group, AE44 magnesium alloy and mild steel does not quickly form a passive film. A research by Abosrra et al. [8] also showed the same trend as AE44 magnesium alloy on mild steel in saline solution containing 1 and $3 \% \mathrm{NaCl}$ and improving surface finish led to shifts in the corrosion potential to more noble states and increased the corrosion rate.

The aim of this work is to compare the effect of roughness on corrosion in $0.5 \mathrm{M} \mathrm{H}_{2} \mathrm{SO}_{4}$ solution for an active-passive metal (nickel) and non-active-passive metal (mild steel).

\section{Experimental procedure}

The mild steel and nickel specimens, were prepared by cutting mild steel and nickel sheet using wire electrical discharge machining (EDM) to pieces of $15 \times 15 \times 1 \mathrm{~mm}$. The sample surfaces were abraded with 60, 120, 180, 240, 320, $400,600,800$ and 1200 grade $\mathrm{SiC}$ papers in a manner that produced unidirectional roughness, washed with double-distilled water, degreased with acetone and dried in warm air. A smaller grit number represents a rougher finish. The letter G, in the used notation (G60 to G1200), stands for grit. After drying, the specimen were placed in a desiccator and then used for experiment. The 0.5 $\mathrm{M} \mathrm{H}_{2} \mathrm{SO}_{4}$ solution was prepared by dilution of analytical grade $\mathrm{H}_{2} \mathrm{SO}_{4}$ with double distilled water.

All electrochemical measurements were conducted in a thermostated conventional three-electrode cell using a Solarton SI-1287 (electrochemical interface) instrument. Mild steel and nickel were used as the working electrode (WE). Only $1 \mathrm{~cm}^{2}$ areas of the samples were exposed to the electrolyte. A saturated calomel electrode (SCE) and a platinum wire were also used as the reference and auxiliary electrodes, respectively. All experiments were carried out in $100 \mathrm{~mL}$ of naturally aerated electrolyte maintained at $25^{\circ} \mathrm{C}$. The scan rate of 
the experiments was $1.0 \mathrm{mV} / \mathrm{s}$. In all experiments, the mild steel and nickel electrodes were allowed to reach their stable open-circuit potential (OCP), which occurred after 30 minutes. The surface morphology of the samples, both before and after corrosion, was studied using a JEOL 5800 SEM at an accelerating voltage of $20.0 \mathrm{kV}$. The EDS spectra were obtained both before and after corrosion to show the changes in the oxygen content in the surface layer. A profilometry technique was used to calculate different roughness parameters including $R_{a}, R_{q}, R_{z}$ and $R_{t}$ before and after corrosion using a Wyko Surface Profiling System NT-1100. The change in all parameters was calculated after corrosion and the relationship between each parameter and corrosion rate was determined.

\section{Results}

\subsection{Potentiodynamic polarization technique}

Figure 1 presents the potentiodynamic polarization curves of mild steel in $0.5 \mathrm{M}$ $\mathrm{H}_{2} \mathrm{SO}_{4}$ solution on surfaces with different unidirectional roughnesses at room temperature. To be able to see the difference between the curves, three curves are presented. The electrochemical parameters, i.e., the open-circuit potential (OCP), the corrosion potential $\left(\mathrm{E}_{\text {corr }}\right)$, the corrosion current density $\left(\mathrm{i}_{\text {corr }}\right)$, and the anodic $\left(b_{a}\right)$ and cathodic $\left(b_{c}\right)$ Tafel constants, shown in Table 1, were collected from the plots from the extrapolation of the polarization curves. The corrosion current was determined by the intersection of the cathodic or the anodic Tafel line with the OCP (potential of zero current in the potentiodynamic curves or $\mathrm{E}_{\text {corr }}$ ). This point determines the potential $\left(\mathrm{E}_{\text {corr }}\right)$ and current density $\left(\mathrm{i}_{\text {corr }}\right)$ for corrosion [9]. Polarization resistance and corrosion rate were also determined using Eqns (1) and (2) [9].

$$
\begin{aligned}
\mathrm{R}_{\mathrm{p}} & =\frac{\beta_{\mathrm{a}} \beta_{\mathrm{c}}}{2.3 \mathrm{i}_{\operatorname{corr}}\left(\beta_{\mathrm{a}}+\beta_{\mathrm{c}}\right)} \\
C R & =K i_{\text {corr }} \frac{E W}{\rho}
\end{aligned}
$$

where $\mathrm{K}=$ constant for converting units, $\mathrm{i}_{\text {corr }}=$ corrosion current density $\left(\operatorname{microamp} / \mathrm{cm}^{2}\right), \rho=$ alloy density $\left(\mathrm{gram} / \mathrm{cm}^{3}\right), \mathrm{EW}=$ alloy equivalent weight (gram/equivalent). It can be seen from the potentiodynamic polarization curves that in the presence of surfaces with different roughness values, there is a decrease in anodic and cathodic current densities and by increasing the roughness from sample G1200 to G60, the curves shifted toward lower corrosion current densities which means lower corrosion rates. According to Table 1 also, by increasing the roughness values corrosion current density and corrosion rate values decreased and polarization resistance values increased. 


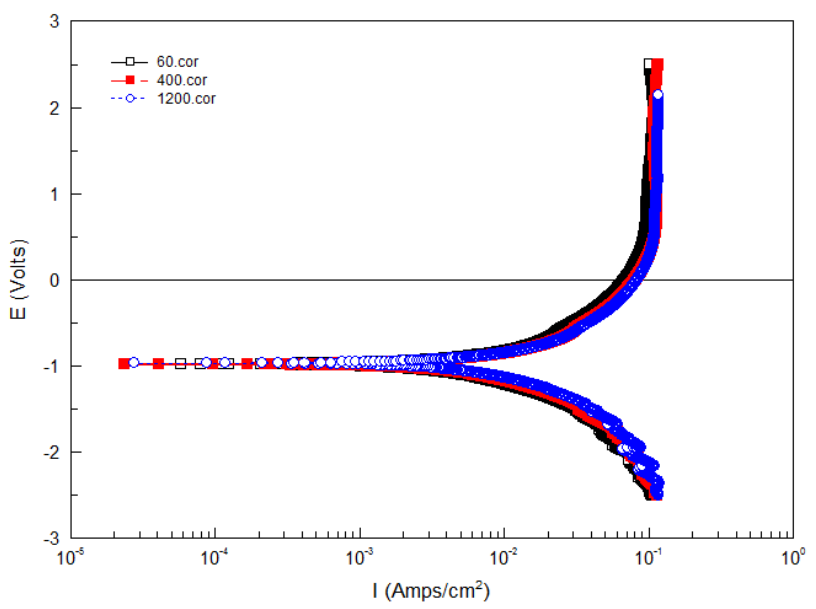

Figure 1: Polarization curves for mild steel samples.

Table 1: Corrosion testing results for mild steel.

\begin{tabular}{r|c|r|c|c|c|c}
\hline Sample & $\begin{array}{c}\mathrm{E}_{\text {corr }} \\
(\mathrm{V})\end{array}$ & $\begin{array}{c}\mathrm{i}_{\text {corr }} \\
\left(\mu \mathrm{A} / \mathrm{cm}^{2}\right)\end{array}$ & $\begin{array}{c}\beta_{\mathrm{a}} \\
(\mathrm{V})\end{array}$ & $\begin{array}{c}\beta_{\mathrm{c}} \\
(\mathrm{V})\end{array}$ & $\begin{array}{c}\mathrm{R}_{\mathrm{p}} \\
\left(\Omega / \mathrm{cm}^{2}\right)\end{array}$ & $\begin{array}{c}\mathrm{CR} \\
(\mathrm{mil} / \text { year })\end{array}$ \\
\hline $\mathrm{G} 60$ & -0.968 & 4141 & 0.295 & 0.570 & 20.46 & 1886 \\
$\mathrm{G} 120$ & -0.971 & 4373 & 0.290 & 0.507 & 18.37 & 1991 \\
$\mathrm{G} 180$ & -0.973 & 4432 & 0.305 & 0.457 & 17.93 & 2018 \\
$\mathrm{G} 240$ & -0.974 & 4724 & 0.291 & 0.513 & 17.05 & 2151 \\
$\mathrm{G} 320$ & -0.973 & 5027 & 0.306 & 0.543 & 16.93 & 2289 \\
$\mathrm{G} 400$ & -0.974 & 6113 & 0.349 & 0.690 & 16.49 & 2784 \\
$\mathrm{G} 600$ & -0.974 & 6255 & 0.358 & 0.688 & 16.35 & 2848 \\
$\mathrm{G} 800$ & -0.973 & 7239 & 0.388 & 0.628 & 14.44 & 3297 \\
$\mathrm{G} 1200$ & -0.973 & 7499 & 0.374 & 0.740 & 14.41 & 3415 \\
\hline
\end{tabular}

The presence of unidirectional roughnesses, on the other hand, slightly modified the current densities of the anodic and cathodic curves and decreased corrosion. The same effect was also observed for the effect of roughness on corrosion rate for AE44 $\mathrm{Mg}$ alloy before [7]. In both cases the metal has no ability to form a passive layer but in the case of other metals which form a passive layer, a reverse trend was observed [1-6]. As it is shown in Figure 1, polarization curves rise to parallel and it is clear that both cathodic and anodic branches show a lower current density indicating that the hydrogen evolution reaction is activation controlled $[10,11]$. Thus, creating the unidirectional roughnesses does not affect the mechanism of this process and has been able to 
affect the corrosion performance. In order to be sure about the consistency of the results all the tests were performed for five times. As it is seen in Figure 2(a), by decreasing the roughness from sample G60 to G1200, ( $\mathrm{i}_{\text {corr }}$ ) and consequently (CR) are increased. In contrast, as can be seen in Figure 2(b), a different corrosion behaviour and a reverse trend was observed in the case of nickel
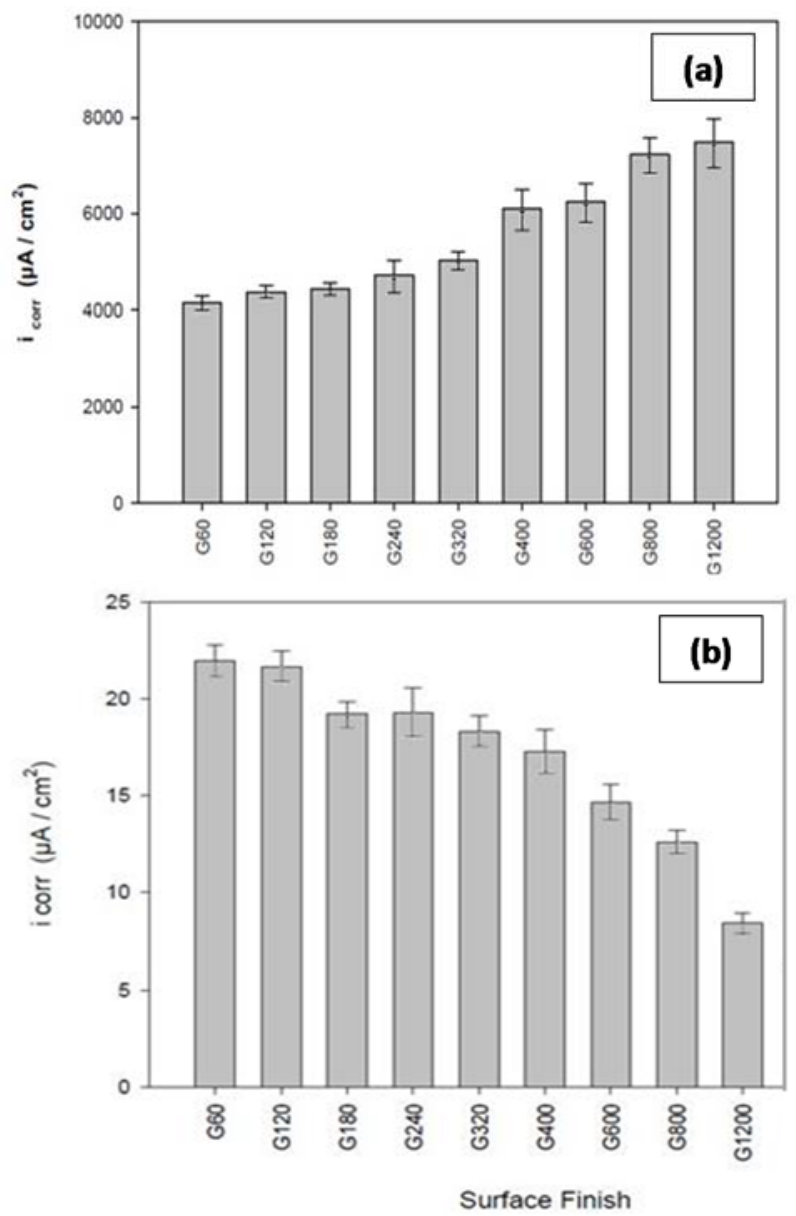

Figure 2: Dependence of $i_{\text {corr }}$ on surface finish of (a) mild steel and (b) nickel.

in $0.5 \mathrm{M} \mathrm{H}_{2} \mathrm{SO}_{4}$ solution on surfaces with different unidirectional roughnesses [6]. As can be seen in previous work done by the authors, by increasing the roughness of nickel surface from sample G1200 to G60, the polarization curves shifted toward higher corrosion current densities which mean higher corrosion rates [12]. 


\subsection{Scanning electron microscopy}

Figure 3(a)-(d) illustrates the SEM micrographs of the surface morphologies of mechanically polished mild steel electrodes with unidirectional roughnesses before and after corrosion. Samples G1200 and G60 are shown as examples of smooth and rough surfaces. It can be seen that the surfaces of electrodes became rougher before corrosion as the grain size of the applied SiC paper increased (higher roughness value). Figure 3(a) presented the smoothest mild steel surface (G1200) with nano size unidirectional roughnesses whereas Figure 3(b) presented sample G1200 surface after corrosion in $0.5 \mathrm{M} \mathrm{H}_{2} \mathrm{SO}_{4}$ solution. Figure 3(c) shows sample G60 as the sample with the roughest surface and Figure 3(d) presents this sample surface after corrosion in $0.5 \mathrm{M} \mathrm{H}_{2} \mathrm{SO}_{4}$ solution. It is clear from the images that the surface of mild steel has changed in both cases. In the case of sample G1200 the metal has been corroded completely and the surface was strongly damaged but there are still some grooves on sample G60, but in a larger scale. Other samples also showed the same trend i.e. on rougher samples more grooves are still visible which shows less degradation on rougher samples. The results obtained from SEM showed good agreement with the results obtained from potentiodynamic polarization technique. In Figure 3(e)-(h), a reverse trend is observed for the nickel samples in $0.5 \mathrm{M} \mathrm{H}_{2} \mathrm{SO}_{4}$ solution namely more degradation on rougher samples and corrosion seemed to be concentrated along the grooves [12]. This trend in change of corrosion versus surface roughness for nickel as an active-passive metal was observed by researchers in the case of stainless steel and aluminium [3,5] which showed poorer corrosion resistance and trapping the corrosive ions on rougher surfaces of active-passive metals.

\subsection{EDS analysis}

Energy dispersive spectroscopy (EDS) was used to characterize the surface and measure the oxygen content of the surface both before and after corrosion testing. Table 2 presents oxygen concentration both before and after corrosion on surfaces of mild steel with different roughnesses. All samples had similar oxygen contents before corrosion testing but the oxygen content increased for all samples after corrosion. Looking at the oxygen content increase of the surface, all samples shoes a significant increase. For the roughest samples (G60-G120) the increase in oxygen content is a little bit less compared to other samples. As demonstrated from the electrochemical results, G60 and G120 exhibited the lowest corrosion rates, and the corrosion rate decreased with increasing roughness.

All the chemical composition analysis for mild steel before the corrosion testing had almost similar results which were expected. After corrosion in all samples specially samples G180 to G1200 there is a significant increase in oxygen content which is related to a severe general corrosion on the surface. The same thing has happened for rougher surfaces (G60 and G120) but with lower amounts of oxygen and less degree of corrosion. The results are in good agreement with SEM and potentiodynamic polarization tests. 

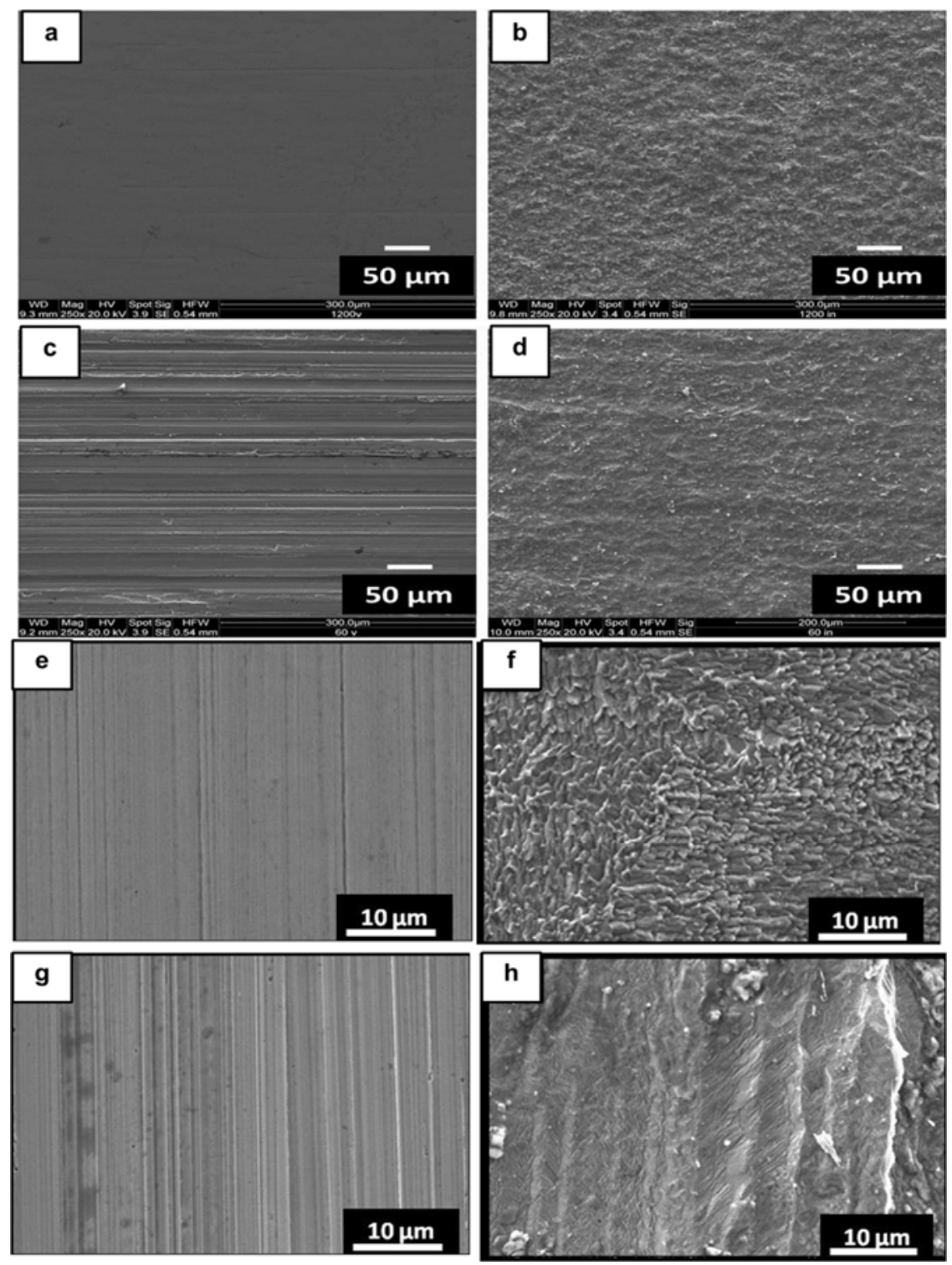

Figure 3: SEM micrograph of mild steel sample G1200 (a) before corrosion; (b) after corrosion, G60; (c) before corrosion; (d) after corrosion and nickel samples G1200; (e) before corrosion; (f) after corrosion and $\mathrm{G60;}$ (g) before corrosion; (h) after corrosion. 
Table 2: EDS results for oxygen contents on the surface of the mild steel samples before and after corrosion.

\begin{tabular}{c|c|c|c}
\hline Sample & $\begin{array}{c}\text { Oxygen wt } \% \text { before } \\
\text { corrosion }\end{array}$ & $\begin{array}{c}\text { Oxygen wt\% } \\
\text { after corrosion }\end{array}$ & $\begin{array}{c}\text { Oxygen wt } \% \\
\text { difference }\end{array}$ \\
\hline G60 & 2.51 & 24.63 & 22.12 \\
G120 & 2.92 & 20.36 & 17.44 \\
G180 & 2.93 & 31.61 & 28.68 \\
G240 & 2.55 & 30.49 & 27.94 \\
G320 & 2.38 & 33.67 & 31.29 \\
G400 & 2.35 & 26.28 & 23.93 \\
G600 & 2.23 & 31.95 & 29.72 \\
G800 & 2.63 & 26.95 & 24.32 \\
G1200 & 2.37 & 28.85 & 26.48 \\
\hline
\end{tabular}

In the case of metals such as aluminum and nickel, the lower corrosion rate was related to the formation of a stable passive film on smoother surfaces as suggested by the authors $[3,12-15]$ but in the case of mild steel no stable passive film is formed and rougher surfaces showed less corrosion and lower oxygen content. Generally, more increase in the oxygen content was observed for mild steel indicating more oxides forms on the surface.

\subsection{Roughness measurement}

Profilometry (Wyko Surface Profiling System NT-1100) was used to characterize the surface and measure the average surface roughness $\left(R_{a}\right)$, rootmean-squared roughness $\left(\mathrm{R}_{\mathrm{q}}\right)$, the average of the ten greatest peak-to-valley separations $\left(\mathrm{R}_{\mathrm{z}}\right)$ and The peak-to-valley difference calculated over the entire measured array $\left(R_{t}\right)$ both before and after corrosion testing. In all parameters, the roughness value for mild steel has increased after corrosion which is due to the formation of corrosion products on the surface. As an example, $R_{a}$ values before and after corrosion testing are listed in Table 3. Last column in this table is a list of $\mathrm{SiC}$ particle size on grinding papers. Nickel also showed an increase in roughness parameters after corrosion which is an indication of the formation of deeper grooves (on rougher surfaces where there is more corrosion) and passive layer (on all surfaces especially smoother surfaces) $[6,12]$. 
Table 3: $\quad \mathrm{R}_{\mathrm{a}}$ values before and after corrosion testing on mild steel.

\begin{tabular}{r|c|c|c}
\hline \multicolumn{2}{c|}{ Sample } & \multicolumn{2}{c}{ Roughness values } \\
\hline No & $\begin{array}{c}\text { SiC particle } \\
\text { size }(\mu \mathrm{m})\end{array}$ & $\begin{array}{c}\mathrm{R}_{\mathrm{a}} \text { (before corrosion } \\
\text { testing) } \\
(\mathrm{nm})\end{array}$ & $\begin{array}{c}\mathrm{R}_{\mathrm{a}} \text { (after corrosion } \\
\text { testing) } \\
(\mathrm{nm})\end{array}$ \\
\hline G60 & 254 & 1446 & 1550 \\
G120 & 102 & 916 & 1688 \\
G180 & 80 & 819 & 1725 \\
G240 & 60 & 401 & 1384 \\
G320 & 40 & 272 & 1460 \\
G400 & 30 & 217 & 1578 \\
G600 & 15 & 185 & 1586 \\
G800 & 13 & 171 & 1588 \\
G1200 & 9 & 128 & 1254 \\
\hline
\end{tabular}

\subsection{Relationship between corrosion rate and roughness}

Figures 4(a) and (b) show the change in corrosion rate as determined by potentiodynamic polarization tests versus average surface roughness parameter $\left(\mathrm{R}_{\mathrm{a}}\right)$ for mild steel and nickel respectively.

By increasing the surface roughness of mild steel corrosion rate decreased. These results are in a great agreement with previous results which investigated the appearance, oxygen concentration and roughness parameters in SEM, EDS and profilometry tests respectively. This is a general trend seen for corrosion of metals with no ability to form a passive layer [7, 8]. This trend is in opposite direction compared to nickel (Figure 4(b)) and aluminum with ability to form a protective passive film [3, 6]. A reverse trend was also reported by $\mathrm{Li}$ and $\mathrm{Li}$ [2] for $\mathrm{Cu}$ in a $3.5 \% \mathrm{NaCl}$ solution which was expected. Looking at the general shape of the plot, we can see that after a limit, decreasing the surface roughness of mild steel dramatically increases the corrosion rate. The rate of change of corrosion rate with roughness decreases before this limit and, for the high roughness values, the corrosion rate appears to reach a plateau. 


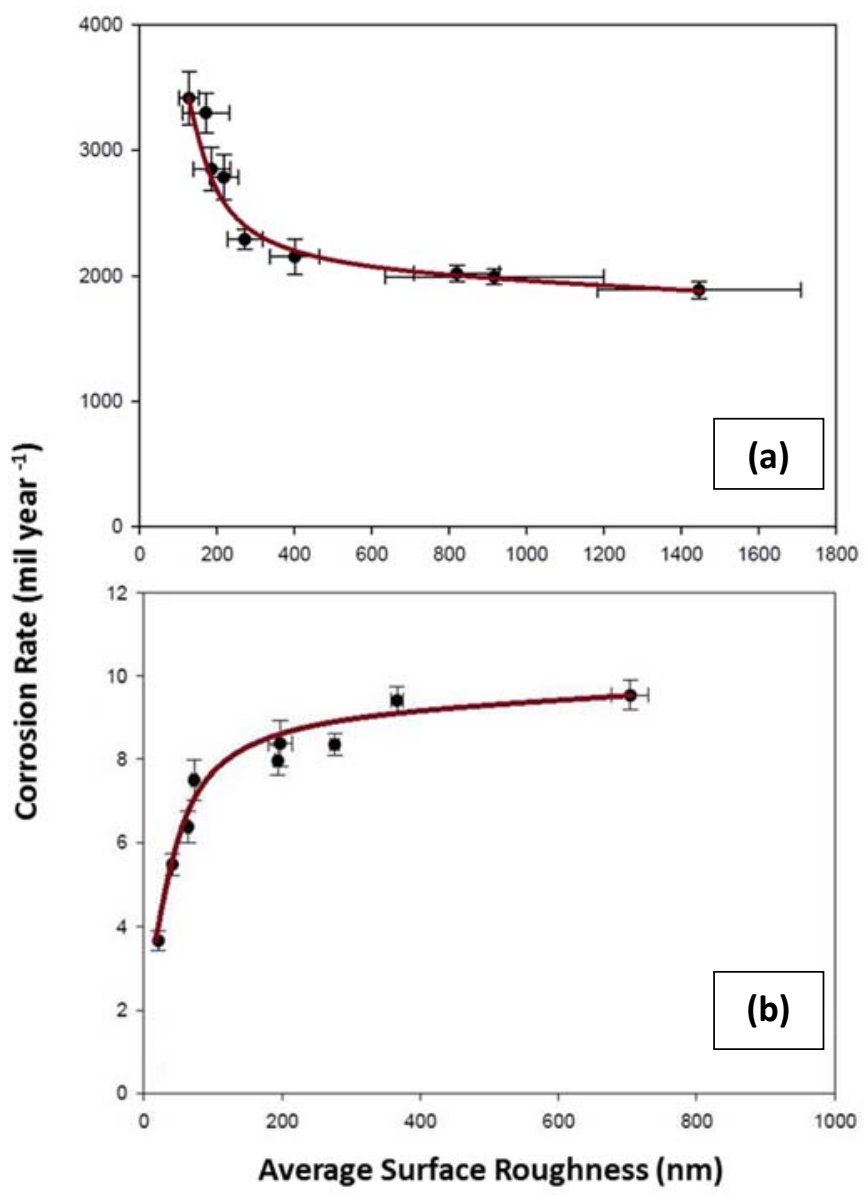

Figure 4: Dependence of corrosion rate of (a) mild steel and (b) nickel on $\left(\mathrm{R}_{\mathrm{a}}\right)$.

\section{Discussion}

The result obtained in this work was that mild steel with smoothest polished surfaces (G1200) showed the highest corrosion rate compared to surfaces with higher roughness values. This can be attributed to the high rate of corrosion propagation after initiation. It is said that localized corrosion is controlled by the diffusion process and in this case once the corrosion started, it propagated at a fast rate due to the continuous diffusion process and the formation of acid media at the bottom of the grooves [8]. The results are in a great accordance with the observations of Alvarez on AE44 Magnesium alloy which has similar characteristics as mild steel (no ability to form a stable passive film) [7]. These trends are opposite of the trends seen in the literature for aluminium, nickel, copper, titanium and stainless steel, which include the rough surfaces limiting 
diffusion out of the forming pits, more available active sites on the rough surfaces, and fast formation of a stable oxide film on the smoother surfaces [3, $16]$.

On mild steel and also magnesium [7], since there is no stable protective passive film on both smooth and rough surfaces, the active sites would be equally available on both surfaces. But there are some grooves which are left from polishing process that act like active sites. These grooves exist more on the surfaces with higher roughness values. Corrosion products and corrosive ions are trapped in such grooves which will result in more corrosion on rough surfaces. But this is not the whole story, because the rough surface might still possess some of the corrosion products, which is said to be less reactive than the bulk of metals. Same thing could also occur on mild steel or magnesium. Therefore, the possibility of corrosion will be decreased on rougher surfaces of mild steel because of the corrosion product layer that exists on the surface. But despite of having fewer places for corrosion nucleation there would be more corrosion on smoother surfaces because there is no protection on the polished surface since the places for corrosion to occur would be more in contact with corrosive solution.

It is said that a rougher surface would prevent the diffusion of the corrosive ions out of the grooves and forming pits by trapping the ions [3], but simultaneously a rougher surface on mild steel surfaces also could prevent the diffusion of the corrosive ions into the grooves [7]. Thus, the limited diffusion of the aggressive ions into the grooves would reduce the corrosion on the rougher surface. But on smooth mild steel surface which has no corrosion product layer or a passive film, corrosion is dependent on the diffusion of the corrosive ions onto the surface because there would be nothing to prevent the corrosion [3]. In the case of metals with no ability to form a passive layer, no repassivation of the smooth surface will occur, unlike stainless steel, nickel or aluminum, but instead more corrosive ions will be in contact with the surface and help the occurrence of corrosion.

So, it is suggested that corrosion is dependent on both surface roughness and the ability of the material to form a protective passive film.

\section{Conclusion}

The surface roughness of mild steel as a metal with no ability to form a passive layer showed a significant effect on its corrosion resistance. A rougher surface has both a slight amount of corrosion product layer remaining, as well as a rougher topography that can prevent the corrosive ions from diffusing close to the surface to initiate corrosion but the smoother surface is corroded more quickly because the smoother surface has nothing preventing corrosion while the rougher surface. For nickel, low surface roughness promotes the formation of a stable passive film and in rougher samples, there is a greater contact area between the corrosive solution and metal together with trapping of corrosive ions in the deep grooves leading to processes such as pitting. 
Potentiodynamic polarization technique was used to measure corrosion parameters related to samples with different roughness values. Less corrosion was observed on rougher samples of mild steel and by decreasing the roughness, corrosion rate increased. A reverse trend was observed for nickel.

SEM micrographs showed more degradation on smoother surface of mild steel but in the case of rougher surfaces some grooves are still visible in a larger scale. The micrograph for nickel showed that the corrosion pits were preferentially aligned along the grooves suggesting that the deep valleys on the ground surface were favourable sites for corrosion nucleation.

EDS analysis also measured oxygen content before and after corrosion and different elements were characterised from the peak analysis. Less increase in oxygen content was observed on rougher samples of mild steel. On nickel, however, the increases in oxygen content especially on smoother surfaces could be indicative of the formation of a stable passive film.

Profilometry were utilized to measure different roughness parameters to investigate corrosion. By increasing the roughness in mild steel, all roughness parameters had the same trend in corrosion rate (decreased and plateaued) and rougher samples showed less increase in roughness after corrosion. For nickel, by increasing the roughness corrosion rate increased and plateaued.

\section{References}

[1] Cabrini M, Cigada A, Rondell G \& Vicentini B, Effect of different surface finishing and of hydroxyapatite coatings on passive and corrosion current of Ti6Al4V alloy in simulated physiological solution, Biomaterials, 18 (11), pp. 783-787, 1997.

[2] Li W \& Li DY, Influence of surface morphology on corrosion and electronic behavior, Acta Materialia, 54 (2), pp. 445-452, 2006.

[3] Suter T, Müller Y, Schmutz P \& von Trzebiatowski O, Microelectrochemical studies of pit initiation on high purity and ultra high purity aluminum, Advanced Engineering Materials, 7 (5), pp. 339-348, 2005.

[4] Walter R \& Kannan MB, Influence of surface roughness on the corrosion behaviour of magnesium alloy, Materials \& Design, 32 (4), pp. 23502354, 2011.

[5] Burstein G \& Vines S, Repetitive nucleation of corrosion pits on stainless steel and the effects of surface roughness, Journal of The Electrochemical Society, 148 (12), pp. B504-B516, 2001.

[6] Toloei AS, Stoilov V \& Northwood DO, The effect of different surface topographies on the corrosion behaviour of nickel, WIT Transactions on Engineering Science, 77, pp. 193-204, 2013.

[7] Alvarez RB, Martin HJ, Horstemeyer MF, Chandler MQ, Williams N, Wang PT \& Ruiz A, Corrosion relationships as a function of time and surface roughness on a structural ae44 magnesium alloy, Corrosion Science, 52 (5), pp. 1635-1648, 2010. 
[8] Abosrra L, Ashour AF, Mitchell SC \& Youseffi M, Corrosion of mild steel and $316 \mathrm{~L}$ austenitic stainless steel with different surface roughness in sodium chloride saline solutions. WIT Transactions on Engineering Sciences, 2009.

[9] Roberge P, Corrosion engineering principles and practice, 1st ed.: New York, McGraw-Hill, 2008.

[10] Slepski P, Gerengi H, Jazdzewska A, Orlikowski J \& Darowicki K, Simultaneous impedance and volumetric studies and additionally potentiodynamic polarization measurements of molasses as a carbon steel corrosion inhibitor in $1 \mathrm{M}$ hydrochloric acid solution, Construction and Building Materials, 52, pp. 482-487, 2014.

[11] Bouklah, Krim O, Messali M, Hammouti B, Elidrissi A \& Warad I, A pyrrolidine phosphonate derivative as corrosion inhibitor for steel in $\mathrm{H}_{2} \mathrm{SO}_{4}$ solution, Der Pharma Chemica, 3 (5), pp. 283-293, 2011.

[12] Toloei, AS, Stoilov, V, and Northwood, DO, An electrochemical impedance spectroscopy and potentiodynamic polarization study of the effect of unidirectional roughness on the corrosion of nickel, International Journal of Computational Methods and Experimental Measurements, 2(3), pp. 243-254, 2014.

[13] Toloei AS, Stoilov V \& Northwood DO, A new approach to combating corrosion of metallic materials, Applied Surface Science, 284, pp. 242-247, 2013.

[14] Toloei A, Stoilov V \& Northwood DO, The effect of creating different size surface patterns on corrosion properties of nickel. Proc of ASME International Mechanical Engineering Congress \& Exposition (IMECE2012) Houston, USA, 2012.

[15] Toloei A, Stoilov V \& Northwood DO, The relationship between surface roughness and corrosion, ASME International Mechanical Engineering Congress \& Exposition, San Diego, California, USA, 65498, 2013.

[16] Zuo Y, Wang $\mathrm{H} \&$ Xiong $\mathrm{J}$, The aspect ratio of surface grooves and metastable pitting of stainless steel, Corrosion Science, 44 (1), pp. 25-35, 2002. 